\title{
Prevalence of Legionella Pneumophila in Production Networks and Distribution of Domestic Hot Water in Morocco
}

\author{
Mariam Mekkour ${ }^{1,2}$, El Khalil Ben Driss², Nozha Cohen ${ }^{1, *}$ \\ ${ }^{1}$ Division de Microbiologie et d'Hygiène des Produits et de l'Environnement, Institut Pasteur du Maroc, Casablanca, 20360, Maroc \\ ${ }^{2}$ Département de Biologie, Faculté des Sciences-Université Abdelmalek Essaadi, Tétouan, 93 000, Maroc
}

\begin{abstract}
The goal of this study was to evaluate the prevalence of Legionella pneumophila specie in hot water samples from tanks and ecological networks of production and distribution of domestic hot water in Morocco. To accomplish this study, 156 samples of hot water, were collected from thirty four structures' from January 2009 to December 2010, were analyzed to search and enumeration of Legionella pneumophila by culturing onto a selective medium. The results of all samples showed that Legionella pneumophila was detected in $31.5 \%$ of total samples analyzed $67.4 \%$ with a load above the limit tolerated by the regulations. The serological survey showed that $37 \%$ of isolates are Legionella pneumophila serogroup 1 while $63 \%$ correspond to serogroup 2-15 whose serogroup 6 was the most frequently isolated (37\%). The results of this study show that Morocco has a high frequency in Legionella pneumophila serogroup 1, which is primarily responsible for the majority of Legionnaires' disease, which will encourage the authorities to take necessary measures for the surveillance and preventive actions for monitoring of the disease legionellosis in Morocco.
\end{abstract}

Keywords Aerosol, Biofilms, Hot Water, Legionnaires' Disease, Legionella Pneumophila

\section{Introduction}

Legionella pneumophila, the agent responsible for Legionnaires' disease and Pontiac fever[1], was first discovered after a large outbreak in an American hotel in 1976. This bacterium has been found in various aquatic environments, e.g., ponds, rivers, lakes[2] as well as in soil and his survival depend upon several factors, such as the presence of protozoa[3], heterotrophic bacteria, $\mathrm{pH}$, temperature, oxygen level, and plumbing fixture materials[4]. L. pneumophila, for which 14 serogroups have been identified, is the species most commonly associated with disease outbreaks[5]. $L$. pneumophila does not pose a serious health risk due to its low amounts in natural habitats. However, man-made systems serve as amplifiers for $L$. pneumophila by providing suitable conditions for growth and multiplication[6]. Numerous epidemic investigations have convincingly demonstrated that domestic hot water systems have served as sources of legionellae infection[7]. Frequently, legionellae has been isolated in high numbers from water, sediments[8] and slimes in cooling water systems[6]. Contaminated aerosols, acquire the infection and inhalation of these aero-

* Corresponding author:

nozha.cohen@pasteur.ma (Nozha Cohen)

Published online at http://journal.sapub.org/env

Copyright (C) 2012 Scientific \& Academic Publishing. All Rights Reserved sols presumably produces Legionnaires' diseas[9], but No interhuman transmission has yet been found[10]. In this study, the existence and distribution of L. pneumophila were investigated to find the sources of previously reported sporadic cases of Legionnaires' disease in Morocco. The goal of this study was to evaluate the frequency of colonization by Legionella pneumophila in hot water systems of the different structures' in Morocco.

\section{Materials and Methods}

\subsection{Sample Collection}

From January 2009 through December 2010, a total of 156 water samples were collected from 26 hotels, 6 factories and 2 gyms of nine towns representative of different Moroccan regions. The first jet of hot water was drawn from the bathroom outlets (showers or taps) and placed in sterile bottles. In order to neutralize the residual free chlorine, $10 \%$ sodium thiosulphate was added in sterile bottles for bacteriological analysis $(1 \mathrm{ml} / \mathrm{L})$. Only sterile bottles were employed throughout the study. Water samples were taken to the laboratory and immediately processed.

\subsection{Microbiologic Analysis}

To detect Legionella pneumophila, 1-L water samples were concentrated by sterile cellulose nitrate membrane 
filters whose a pore size is $45 \mu \mathrm{m}$ (Sartorius AC, Goettingen, Germany). The intact membranes were aseptically removed, placed into sterile $5 \mathrm{~mL}$ screw-capped containers. Each concentrated water sample was sonicated for tow min to dislodge bacterial cells from the membranes using a model B2 210-DTH ultrasonic cleaner (Danbury, USA). $2 \mathrm{ml}$ of the suspension was pre-treated with heat $\left(50^{\circ} \mathrm{C}\right.$ water bath during $30 \mathrm{~min})$ and the other $2 \mathrm{ml}$ was pre-treated with acid $(2 \mathrm{ml}$ of $\mathrm{HCl}-\mathrm{KCl}$ solution, $\mathrm{pH} 2.0$ ). The heat and acid pre-treatment of concentrated water samples were used as a selective method to reduce the numbers of non-Legionella bacteria as previously described[11,12]. Plates containing selective medium for growth and isolation of Legionella-CYE- agar (base) supplemented with BCYE $\alpha$ growth-supplement and GVPC selective supplement (Legionella-Combi-Pack, Merck E, Darmstadt, Germany) were inoculated with a $0.1 \mathrm{ml}$ of hot pre-treatment sample and with a $0.2 \mathrm{ml}$ of acid pre-treatment sample. All the samples were incubated at $35^{\circ} \mathrm{C} \pm 2{ }^{\circ} \mathrm{C}$ with $2.5 \% \mathrm{CO} 2$ in a humid atmosphere for 10 days and examined at 3,5 , and 10 days. Colonies suspected of being of Legionella were subcultured on BCYE and on blood agar plates; those that failed to grow on the blood agar plates but grew on BCYE with cysteine were identified by the latex agglutination method, which also allowed us to distinguish serogroup 1 from serogroups 2-14 (Slidex Legionella- kit, BioMérieux, Lyon, France). Our positive control was an antigen suspension of $L$. pneumophila 1 (ATCC 33152) obtained from a separate culture. For L.pneumophila serogroup subclassifications $2,3,4,5,6, .$. , 14 were identified by the agglutination technique of latex particles sensitized with monoclonal antibodies (reagent supplied by BioMérieux).

\section{Results}

Of the 156 samples analyzed above, 118 came from hotels, 33 from Factories and 5 from gyms of different areas in Morocco; the results of all samples were negative for $L e$ gionella only in $13(38.2 \%)$ structures'. Legionella pneumophila were detected in 49 samples (31.5\%), 43 (36.5\%) of which were from hotels, $2(40 \%)$ of which were from gyms and $4(12.2 \%)$ of which were from Factories (Table 1).

Table1. Prevalence of Legionella pneumophila in the hot water distribution systems.

\begin{tabular}{cccc}
\hline Organisms(n) & $\begin{array}{c}\text { No, of water } \\
\text { samples }\end{array}$ & $\begin{array}{c}\text { No, of positive } \\
\text { samples (\%) }\end{array}$ & $\begin{array}{c}\text { Serogroups } \\
\text { isolated }\end{array}$ \\
\hline Hotels $(\mathrm{n}=26)$ & 118 & $43(36.5)$ & $\begin{array}{c}\text { Lp1, Lp3, } \\
\text { Lp4, Lp6, } \\
\text { Lp4-8 C.r }\end{array}$ \\
\hline Gyms $(\mathrm{n}=2)$ & 05 & $2(40)$ & Lp1, Lp6 \\
\hline Factories $(\mathrm{n}=6)$ & 33 & $4(12.2)$ & Lp1, Lp6 \\
\hline Total $(\mathrm{n}=34)$ & 156 & $49(31.5)$ & - \\
\hline
\end{tabular}

Lp: Legionella pneumophila; C.r.: Cross-reaction.

The most common species identified were $L$. pneumophila serogroup 1 and 6 (each one 37\%) (Table2). The structures' positive for L. pneumophila serogroup 1 and 6 were distributed through all of the different geographical areas within the country. The colony count was lower than 250 colony-forming unit (CFU)/1L in $8(16.3 \%)$ samples, between 250 and $1,000 \mathrm{CFU} / 1 \mathrm{~L}$ in also $8(16.3 \%)$ samples, and higher than $1,000 \mathrm{CFU} / 1 \mathrm{~L}$ in $22(45 \%)$ samples (Table 3). We found that in $18(53 \%)$ structures' including 15 hotels, 2 factories and one gym, the colony count exceeded 250 $\mathrm{CFU} / 1 \mathrm{~L}$ in at least one sample.

Table2. Distribution of serogroups of L. pneumophila from Moroccan structures' by isolated hot water samples.

\begin{tabular}{cc}
\hline Serogroups of Legionella pneumophila & $\mathrm{n}(\%)$ \\
\hline Serogroup 1 & $18(37)$ \\
\hline Serogroup 3 & $2(4)$ \\
\hline Serogroup 4 & $7(14)$ \\
\hline Serogroup 6 & $18(37)$ \\
\hline Serogroup 4-8 cross-reaction & $4(8)$ \\
\hline
\end{tabular}

\section{Discussion}

Legionella are readily found in natural aquatic bodies with some species been recovered from soil[13,14]. Studies have shown that Legionella species are present in all segments of community water supplies, water treatment structures'[15]. The aquatic environment of this bacteria also includes man made habitats such as cooling towers, evaporative condensers, whirlpool spas, decorative fountains, air conditioner water systems, and potable-water distribution systems, so the colonization of this artificial habitats by L. pneumophila depends on a combination of several factors, including water temperature, sediments accumulation, and commensal microflora[16,17]. Bacterial transmission to humans is most commonly accepted to be via droplets generated from these environmental sources. The epidemiological evidence suggests that the aerosol travels and remains infective from several hundreds meters to a few kilometers[18]. Our study showed that Morocco is not exempted from the list of countries where Legionella pneumophila is found (the most virulent species of Legionella), this bacteria has been isolated from a wide variety of water types, such as potable water of hotels, factories and gyms. Moreover, several authors have described the isolation of this bacteria from showers, cooling towers and boilers[11,19], which is in agreement with the findings of the present study.

The use of selective media like BCYE agar medium has proven to be very important in the isolation of Legionella and L. pneumophila in this study as demonstrated by other researchers in this field[20,21]. Our study also showed that the medium alone was not sufficient for the selective isolation of L. pneumophila because environmental organisms seemed to come through despite the incorporation of antibiotics that selectively inhibit the growth of competing microflora of the environments including fungi[13]. This study is in line with other studies where the BCYE with antibiotics was used in the detection and isolation of Legionella from the environments[13,22]. 
Table 3. Concentration for each serogroup of L.pneumophila isolated by colony count from hot water samples.

\begin{tabular}{ccccccc}
\hline \multirow{2}{*}{ CFU/1L } & \multicolumn{7}{c}{ No. of each serogroups L.pneu mophila $(\%)$} \\
\cline { 2 - 6 } & SG1 $(\mathrm{n}=18)$ & SG3 $(\mathrm{n}=2)$ & SG4 $(\mathrm{n}=7)$ & SG6 $(\mathrm{n}=18)$ & SG4-8 C.r(n=4) & Total, n $(\%)$ \\
\hline $\mathrm{X}<250$ & $2(11)$ & - & $2(28.5)$ & $4(22.2)$ & - & $8(16.3)$ \\
\hline $250 \geq \mathrm{X}<10^{3}$ & $2(11)$ & $1(50)$ & $1(14.5)$ & $4(22.2)$ & - & $8(16.3)$ \\
\hline $10^{3} \geq \mathrm{X}<10^{4}$ & $3(16.6)$ & - & $2(28.5)$ & $5(27.8)$ & $1(25)$ & $11(22.4)$ \\
\hline $\mathrm{X} \geq 10^{4}$ & $11(61)$ & $1(50)$ & $2(28.5)$ & $5(27.8)$ & $3(75)$ & $22(45)$ \\
\hline
\end{tabular}

CFU: Colony-Forming Unit; SG: Serogroup

Our study provide information about the prevalence of $L$. pneumophila in hot water distribution systems, which are located in Morocco. Therefore, it is best to assume that any given system can harbor the organism, and that routine, continuous microbiological control practices should be implemented to minimize the risk of $L$. pneumophila amplification and associated disease. In European hotel water systems, Legionella colonization ranged from $27 \%$ to $75 \%$ in several studies[23,24].

In Moroccan hot water distribution systems Thai and colleagues in 2009 reported L. pneumophila colonization rates as $32.5 \%[25]$, this result is similar to the value reported by our study which is $31.5 \%$. L. pneumophila $2-14$ accounted for $63 \%$, whose the serogroup 6 is most commonly isolated $(37 \%)$, a similar result was found by Thai and colleagues (60\% for serogroup 2-14)[25]. The percentage of hot water sampled in this study with a $L$. pneumophila count $>10.000$ ufc/L was higher $(45 \%)$ than that found in the literature $13.5 \%$ in Italy, $7.8 \%$ in Turkey and $4.2 \%$ in Greece[26,16,27]. Our study evidenced also a high percentage (37\%) for L. pneumophila serogroup 1 with $61 \%$ of value is more than $10.000 \mathrm{ufc} / \mathrm{L}$. Although the distribution of serotypes causing community-acquired or hospital-acquired Legionnaires' disease varies by geographic region, about $90 \%$ of Legionnaires' disease cases are due to L. pneumophila, and predominant serogroup 1 of L. pneumophila accounts for $84 \%$ of the case[28,29]. Moreover the serogroup 6 is more common in nosocomial strains and more likely to be associated with poor outcome[30]. In contrast to clinical specimens, L. pneumophila serogroups 2 to 14 accounted for more than $50 \%$ of the isolates obtained from environmental water systems in several studies.

From the literature and result obtained in this study we can supported the idea that some of organisms that were included in this study posed a risk for Legionnaires' disease at the time of the study, due to the high concentrations of $L$. pneumophila serogroup 1 and the number of positive water distribution systems which exceeded the safety levels of the European Surveillance Scheme for Travel Associated Legionnaires' Disease guidelines.

The incidence of Legionnaires' disease depends on the degree of contamination of the aquatic reservoir, the susceptibility of people exposed to that water, differences in virulence among Legionella species, and the intensity of the exposure [30].

In a previous study in Morocco 2009, two cases were identified for legionellosis, this group of patients consisted of a man and a woman aged respectively 39 and 72 years old.
Patients had the following risk factors: the man was a smoker and the woman was diabetic and had heart disease, renal disease and a pulmonary. Another suspected case, that of an elderly woman 50 years old working in a hospital and stayed in a hotel; it has similar symptoms to Legionnaires' disease such as high fever, myalgia, headache and digestive disorders. Urinary antigen detection (more than three weeks after onset of symptoms)

in the patient was negative[25]. Legionellosis can easily be confused with symptoms of flu[31], and is clinically indistinguishable from other causes of pneumonia, so the diagnosis of Legionnaires' disease requires specific diagnostic tests. The World Health Organization observed since Twenty one years ago, that the morbidity and mortality due to sporadic and epidemic legionellosis was under-reported in most health statistics[32]. We believe that this scenario still exists in many countries especially in Africa. In Morocco, the direction of Epidemiology and the fight against the diseases do not have to date data on this disease. The results of our study show that the L. pneumophila exists in Morocco. However, there is no routine and periodic surveillance and reporting of this bacteria's infection.

\section{Conclusions}

we suggest that clinicians should apply the whole spectrum of laboratory methods for the diagnosis of legionnaires ' disease and take samples for culture wherever possible, and we recommend that targeted behavioral control messages be directed at the sectors of population in order to warn them against the possible risks of $L$. pneumophila infection from environmental sources. Routine monitoring of environmental water for L. pneumophila is expected to prove helpful in efforts to reduce the bacterial contamination of water systems and is also expected to facilitate the development of a more active prevention strategy for Legionnaires' disease. Additionally, further study will require that the focus be kept on correlation analysis by clustering between environmental and clinical isolates of Legionella species. Thus, the findings of this study highlight the importance of understanding the epidemiology and ecology of L. pneumophila from public facilities in terms of public health; in this regard, our findings corroborate and reinforce the recommendations made in several previous studies[33,34].

\section{ACKNOWLEDGMENTS}


We express our gratitude to our coworkers who provided assistance. We also thank Dr. Fabien SQUINAZI (Laboratoire d'Hygiène de la Ville de Paris) and Dr. Sophie JARRAUD (Centre National de Référence de Legionelles, Lyon) for their help to make serotyping of Legionella pneumophila strains.

\section{REFERENCES}

[1] Yu VL., 1993, Could aspiration be the major mode of transmission for Legionella., Am. J. Med. 95:13-15

[2] Yamamoto, H., Sugiura, M., Kusunoki, S., Ezaki, T., Ikedo, M., and Yabuuchi, E., 1992, 'Factors stimulating propagation of Legionellae in cooling tower water., Appl. Environ. Microbiol. 58(4):1394-1397

[3] Cirillo, J.D., Falkow, S., Tompkins, L.S., 1994, Grow of Legionella pneumophila in Acanthamoeba castellani enhances invasion. InfectImmun. 62:3254-3261

[4] Stout, J.E., Yu, V.L., Best, M.G., 1985, Ecology of Legionella pneumophila within water distribution systems. Appl Environ Microbiol. 49:221-228

[5] Benson, R.F., and Fields, B.S., 1998, Classification of the genus Legionella., Sem. Respiratory Infect. 13(2):90-99.

[6] Bentham, R.H., 2000, 'Routine sampling and the control of Legionella spp. in cooling tower water systems'. Curr. Microbiol. 41:271-275

[7] Bosch, X., 2001, 'Legionnaires' outbreak in Spanish town may be largest ever'. Lancet. 358:220-221

[8] Atlas, R.M., 1999, From environmental habitats to disease pathology, detection and control. Environ. Microbiol. 1(4):283-293

[9] Ishimatsu, S., Miyamoto, H., Hori, H., Tanaka, I., and Yoshida, S., 2001, 'Sampling and detection of Legionella pneumophila aerosols generated from an industrial cooling tower'. Ann. Occu. Hyg. 6(45):421-427

[10] Catalan, V., Garcia, F., Moreno, C., Vila, M.J., Apraiz, D., 1997, Detection of Legionella pneumophila in wastewater by nested polymerase chain reaction., Res. Microbiol. 148 (1):71-78

[11] Fábio, R. S., Carvalho., Annette, S., Foronda., Vivian, H., Pellizari., 2007, Detection of Legionella pneumophila in water and biofilm samples by culture and molecular methods from man-made systems in são paulo - brazil., Brazilian Journal of Microbiology. 38:743-751

[12] Türetgen, I., Sungur, E.I., and Cotuk, A., 2005, Enumeration of Legionella pneumophila in cooling tower water systems. Environmental Monitoring and Assessment. 100:53-58

[13] Terry Alli, O.A., Olusoga, O.D., Adedokun, S.A., and Ogundare, O.E., 2011, Isolation of Legionella pneumophila from surface and ground waters in Osogbo, Nigeria., African Journal of Microbiology Research. 5(18):2779-2785

[14] Steele, T.W., Moore, C.V., Sangster, N., 1990, Distribution of Legionella longbeachae serogroup 1 and other Legionellae in potting soils in Australia. Appl. Environ. Microbiol. 56: 2984-2988

[15] Kuroki, T., Ishihara, T., Ito, K., Kura, F., 2009, Bathwater-associated cases of legionellosis in Japan, with a special focus on Legionella concentrations in water., Jpn J. Infect. Dis. 62:201-205

[16] Erdogan, H, M.D., and Arslan, H, M.D., 2007, Colonization of Legionella Species in Hotel Water Systems in Turkey. International Society of Travel Medicine. 14: 369-373

[17] Abu Kwaik, Y., Gao, L.Y., Stone, B.J., Venkataraman, C., Harb, O.S., 1998, Invasion of protozoa by Legionella pneumophila and its role in bacterial ecology and pathogenesis. Appl. Environ. Microbiol., 64:3127-3133

[18] Nguyen, T.M., Ilef, D., Jarraud, S., et al., 2006, A communitywide outbreak of legionnaires disease linked to industrial cooling towers - how far can contaminated aerosols spread., J Infect Dis. 193:102-111

[19] Kim, B.R., Anderson, J.E., Mueller, S.A., Gaines, W.A., Kendall, A.M., 2002, Literature review - efficacy of various disinfectants against Legionella in water systems, Water Res. 36(18):4433-4444

[20] Azara, A., Piana, A., Sotgiu, G., Dettori, M., Deriu, M.G., Masia, M.D., Are, B.M., Muresu, E., 2006, Prevalence study of Legionella spp. Contamination in ferries and cruise ships. BMC Public Health. 6:100

[21] Bartie, C., Venter, S.N., Nel, L.H., 2003, Identification methods for Legionella from environmental samples. Water Res. 37:1362-1370

[22] Stout, J., Rihs, J., Yu, V., 2003, Legionella. In Manual of Clinical Microbiology Edited by Murray P, Baron E, Jorgensen J, Pfaller M, Yolken R. Washington DC: ASM, pp. $809-823$

[23] Borella, P., Montagna, M.T., Stampi, S., Stancanelli, G., Romano Spica, V., Triassi, M., Marchesi, I., Bargellini, A., Tatò, D., Napoli, C., Zanetti, F., Leoni, E., Moro, M., Scaltriti, S., Ribera, A.G, Santarpia, R., Boccia, S., 2005, Legionella contamination in hot water of Italian hotels. Appl Environ Microbiol. 71:5805-13

[24] Leoni, E., De Luca, G., Legnani, P.P., et al., 2005, Legionella waterline colonization: detection of Legionella species in domestic, hotel and hospital hot water systems. J Appl Microbiol. 98:373-379

[25] Taî, J., Elhabch, D., Hassar, M., Cohen, N., 2009, Enquête Epidémiologique sur la Légionellose et Prévalence de Legionella pneumophila dans Les Eaux Chaudes Sanitaires au Maroc. Les Technologies de Laboratoire. 16:4-9

[26] Napoli, C., Fasano, F., Iatta, R., Barbuti, G., Cuna, T., Montagna, M.T., 2010, Legionella spp. and legionellosis in southeastern Italy: disease epidemiology and environmental surveillance in community and health care facilities., BMC Public Health. 10:660

[27] Yu, P.Y., Lin, Y.E., Lin, W.R., Shih, H.Y., Chuang, Y.C., Ben, R.J., Huang, W.K., Chen, Y.S., Liu, Y.C., Chang, F.Y., Yen, M.Y., Liu, C.C., Ko, W.C., Lin, H.H., Shi, Z.Y., 2008., The high prevalence of Legionella pneumophila contamination in hospital potable water systems in Taiwan: implications for hospital infection control in Asia., Int $\mathrm{J}$ Infect Dis. 
$12: 416-20$

[28] Yu, V. L., Plouffe, J.F., Pastoris, M.C., Stout, J.E., Schousboe, M., Widmer, A., Summersgill, J., File, T., Heath, C.M., Paterson, D.L., and Chereshsky, A., 2002, Distribution of Legionella species and serogroups isolated by culture in patients with sporadic community-acquired legionellosis: an international collaborative survey. J.Infect. Dis. 186:127-128

[29] Helbig, J.H., Bernander, S., Castellani Pastoris, M., et al., 2002, Pan-European study on culture-proven Legionnaires' disease: distribution of Legionella pneumophila serogroups and monoclonal subgroups. Eur J Clin Microbiol Infect Dis. $21: 710-716$

[30] Yu, V.L., Legionella pneumophila (Legionnaires' Disease). In: Mandell, G.L., Bennett, J.E., Dolin, R., eds., 2000. Principles and practice of infectious diseases. 5th Ed .Philadelphia, PA: Churchill Livingstone Inc. 2424-2435
[31] Meena, H. S., Yu, V.L., Muder, R.R., 2005, Legionnaires' Disease in Long-Term Care Facilities: Overview and Proposed Solutions, Ametican Geriatrics Society. 53:875-88

[32] World Health Organization. 1990, Epidemiology, prevention and control of legionellosis: memorandum from a WHO meeting., Bulletin of the World Health Organization. 68(2): $155-164$

[33] Mouchtouri, V.A., Giutzina, G., Kremastinou, J., and Hadjichristodoulou, C., 2010, Legionella species colonization in cooling towers: risk factors and assessment of control measures. Am. J. Infect. Control. 38:50-55

[34] Boccia, S., Laurenti, P., Borella, P., Moscato, U., Capalbo, G., Cambieri, A., Amore, R., Quaranta, G., Boninti, F., Orsini, M., Branca, G., Fadda, G., Spica, V.R., and Ricciardi, G., 2006, Prospective 3-year surveillance for nosocomial and environmental Legionella pneumophila: implications for infection control, Infect. Control Hosp. Epidemiol. 27:459-465 